\title{
Microcephaly-facio-cardio-skeletal syndrome, Hadziselimovic type
}

INSERM

\section{Source}

INSERM. (1999). Orphanet: an online rare disease and orphan drug data base.

Microcephaly-facio-cardio-skeletal syndrome, Hadziselimovic type. ORPHA:217026

Microcephaly-facio-cardio-skeletal syndrome, Hadziselimovic type is a rare syndrome with cardiac malformations (see this term), characterized by prenatal-onset growth retardation (low birth weight and short stature), hypotonia, developmental delay and intellectual disability associated with microcephaly and craniofacial (low anterior hairline, hypotelorism, thick lips with carp-shaped mouth, high-arched palate, low-set ears), cardiac (conotruncal heart malformations such as tetralogy of Fallot; see these terms) and skeletal (hypoplastic thumbs and first metacarpals) abnormalities. 